\title{
Magnesium Alloy Development Using Phase Equilibria Computation and Microstructure Validation
}

\author{
A.A. Luo, R.K. Mishra, B.R. Powell, A.K. Sachdev \\ General Motors Global Research and Development, Warren, MI 48090, USA
}

Keywords: Magnesium alloys, alloy development, computational alloy design, microstructure

\section{Extended Abstract}

This paper summarizes the development of new cast and wrought magnesium alloys using computational thermodynamics and experimental methods. The work illustrates the role of calculated phase diagrams, solidification paths and phases in predicting and interpreting the final microstructure of $\mathrm{Mg}-\mathrm{Al}-\mathrm{Ca}$ and $\mathrm{Mg}-\mathrm{Al}-\mathrm{Sn}$ cast alloy systems and $\mathrm{Mg}-\mathrm{Al}-\mathrm{Mn}$ and $\mathrm{Mg}-\mathrm{Zn}-\mathrm{Ce}$ wrought alloy systems.

The Mg-Al-Ca alloys show excellent creep resistance due to the formation of high-temperature $(\mathrm{Mg}, \mathrm{Al})_{2} \mathrm{Ca}$ phase. Computational thermodynamics calculations and experimental investigation of the $\mathrm{Mg}-\mathrm{Al}-\mathrm{Ca}$ ternary system have validated the earlier development of creep-resistant AX52 (Mg-5Al-2 $\left.\mathrm{Ca}^{1}\right)$ and AX53 (Mg-5Al-3Ca) alloys. The Scheil simulation of alloy solidification has suggested key guidelines of alloy composition design in promoting the thermally stable $(\mathrm{Mg}, \mathrm{Al})_{2} \mathrm{Ca}$ phase, while replacing the less stable $\mathrm{Mg}_{17} \mathrm{Al}_{12}$ in the microstructure. The suppression of the $\mathrm{Mg}_{17} \mathrm{Al}_{12}$ phase can increase the solidus temperature, reduce the freezing range, and increase the latent heat during solidification, all of which contribute to improved castability in the AX53 and AX52 alloys compared with the AX51 (Mg-5Al1Ca) alloy. The quantitative phase equilibrium data, microstructure characterization, as well as the thermal physical properties of the Mg-Al-Ca alloy system generated from this study are important basis for further optimization of alloy composition and microstructure for elevated-temperature applications.
The solidification microstructure and mechanical properties of ascast Mg-Al-Sn alloys have been investigated using computational thermodynamics and experiments. The as-cast microstructure of Mg-Al-Sn alloys consists of $\alpha-\mathrm{Mg}, \mathrm{Mg}_{17} \mathrm{Al}_{12}$ and $\mathrm{Mg}_{2} \mathrm{Sn}$ phases. The amount of $\mathrm{Mg}_{17} \mathrm{Al}_{12}$ and $\mathrm{Mg}_{2} \mathrm{Sn}$ phases formed increases with increasing $\mathrm{Al}$ and/or $\mathrm{Sn}$ content, and show good agreement between the experimental results and the Scheil solidification calculations. Generally, the yield strength of as-cast alloys increases with $\mathrm{Al}$ and/or Sn content, while the ductility decreases. This study has confirmed an early development of Mg-7Al-2Sn alloy for structural applications and led to a promising new $\mathrm{Mg}$ 7Al-6Sn alloy with significantly improved strength and ductility comparable to commercial AZ91 alloy.

AM30 (Mg-3Al-0.3Mn) alloy was developed to have significantly improved extrudability and slightly improved mechanical properties compared to AZ31 alloy. The limited extrudability of AZ31 (Mg-3Al-1Zn) alloy is reported to be caused by incipient melting of the $\mathrm{Mg}_{17} \mathrm{Al}_{12}$ binary phase with a eutectic temperature of $438^{\circ} \mathrm{C}$. Computational phase equilibria and microstructural examination, however, show that $\mathrm{Mg}-\mathrm{Al}-\mathrm{Zn}$ ternary phases with eutectic temperatures as low as $338^{\circ} \mathrm{C}$ are actually present in the AZ31 alloy, which is indeed the real limitation to its extrudability. The significantly improved extrudability of AM30 alloy (Mg-3Al$\mathrm{Mn}$ ) is due to the absence of these zinc-containing eutectic phases. In the Mg-Zn-Ce (ZE) system, Zn provides strength through solid solution strengthening, while Ce increases the ductility by creating a favorable texture. Computational thermodynamics and experimental work confirm a final solidification structure of the $\mathrm{ZE}$ alloys: $\alpha(\mathrm{Mg})+\mathrm{Mg}_{7} \mathrm{Zn}_{3}+\mathrm{MgZn}$. Ce was found not tied up by $\mathrm{Zn}$ and $\mathrm{Mg}_{7} \mathrm{Zn}_{3}$ exists at temperatures above $325^{\circ} \mathrm{C}$ and decomposes into $\alpha(\mathrm{Mg})$ and $\mathrm{MgZn}$ at below $325^{\circ} \mathrm{C}$, a potentially age-hardening phase.

\footnotetext{
${ }^{1}$ All compositions in wt.\%.
} 